Bioelectrochemistry and Bioenergetics, 20 (1988) 83-98

A section of J. Electroanal. Chem., and constituting Vol. 254 (1988)

Elsevier Sequoia S.A., Lausanne - Printed in The Netherlands

\title{
On the audio- and radio-frequency dielectric behaviour of anchorage-independent, mouse L929-derived LS fibroblasts *
}

\author{
Christopher L. Davey ${ }^{\star \star}$ and Douglas B. Kell \\ Department of Botany and Microhiology, Unimersity College of Wales, Aherystwyth, Dyfed SY23 3DA (Great \\ Britain)
}

Richard B. Kemp and R.W. John Meredith

Department of Zoology, University College of Wales, Aberystwyth, Dyfed SY23 3DA (Great Britain)

(Received 8 October 1987)

\begin{abstract}
The utility of dielectric methods as a means for estimating the biomass of animal cells in suspension culture was assessed, using mouse L929-derived LS fibroblasts. The dielectric increment of the $\beta$-dispersion was found to be a linear function of both cell number $\left(30-70\right.$ permittivity units per $10^{6}$ cells $/ \mathrm{ml}$, depending on the batch of cells) and volume fraction in the range measured (up to $1.28 \times 10^{8} \mathrm{cells} / \mathrm{ml}$, volume fraction $=0.14$ ). The notional distribution of relaxation times as encompassed in the Cole $/ \mathrm{Cole}$ $\alpha(0.13 \pm 0.03 \mathrm{SD})$ was rather modest. If the cells were treated as spherical shell capacitors of their observable diameter and number, the apparent capacitance of the plasma membrane was some 1.9-4.0 $\mu \mathrm{F} / \mathrm{cm}^{2}$. This value significantly exceeded those $\left(0.5-1 \mu \mathrm{F} / \mathrm{cm}^{2}\right)$ usually encountered or claimed, due predominantly to the possession by these cells of numerous plasma membrane protrusions. As the osmolarity of the suspending medium was increased using the non-permeant solute sorbitol, the apparent specific capacitance of the plasma membrane and the Cole/Cole $\alpha$ were increased, whilst the dielectric increment per $10^{6}$ cells $/ \mathrm{ml}$ was unchanged. In addition, a secondary $\beta$-dispersion, with a characteristic frequency greater than that of the main $\beta$-dispersion, became increasingly prominent as the medium osmolarity was increased. It is proposed that this $\beta_{2}$-dispersion is dominated by a Maxwell-Wagner mechanism taking place in the region of the plasma membrane protrusions of these cells.
\end{abstract}

\section{INTRODUCTION}

There is a widespread and current interest in the dielectric behaviour of biological systems, not least because of an increasing awareness of the possible physiologi-

\footnotetext{
ऋ Presented at the 9th BES Symposium on Bioelectrochemistry and Bioenergetics, Szeged (Hungary). 1-5 September 1987.

* To whom correspondence should be addressed. 
cal effects elicited by the absorption by tissues of non-ionizing electromagnetic radiation (see, for example, refs. 1-16). In addition, some of our own recent studies in this area have been motivated by an awareness of the enormous potential utility of ac electrical methods in a variety of biosensing devices [17-21]. In this latter work, we have concentrated in particular, to date, upon exploiting the classical RFor " $\beta$ "-dispersion possessed by all membranc-enclosed vesicles, for the estimation of cellular biomass during microbial fermentations. It was shown [17-21] that measurement of the RF permittivity of microbial suspensions at an appropriate frequency does indeed provide the prospect of an almost ideal "biomass probe".

Since the basis of the dielectric method of biomass estimation, and of much of the $\beta$-dispersion itself [7,14-16,22-24], lies in the possession by the micro-organismis of a relatively ion-impermeable lipid membrane, the method should be applicable to all types of biological cell. Since there is also much interest in the exploitation of animal cell cultures for the production of a variety of bioactive products (e.g. refs. 25-27), we considered it worthwhile to seek to extend the above type of approach to the estimation of biomass to animal cell cultures, for which existing methods (e.g. refs. 28-31) are neither real-time nor satisfactory. To this end, it became important to understand the dielectric hehaviour of animal cells (and its mechanistic basis) in washed cell suspensions.

The RF dielectric properties of animal cells have been studied by a number of workers, who in all cases observed a substantial $\beta$-dispersion [3,32-36]. Most groups have explained their data on the basis of the models developed by Schwan [1], Pauly and Schwan [37] and Hanai and co-workers [38-41], which, while derived for spherical and ellipsoidal membrane-enclosed vesicles, permit one to estimate, amongst other parameters, the capacitance per unit area of the cellular plasma membrane. This is generally recognized to take a value of some $1 \pm 0.5 \mu \mathrm{F} / \mathrm{cm}^{2}$. However, as foreshadowed by early work of Cole, Iida and Rothschild [42-44], and as recently recognized in this context by Irimajiri et al. [35,36], animal cells frequently exhibit a highly irregular, and perhaps fractal [45], surface morphology. This can give rise to a significant overestimation of the membrane capacitance if this latter is assessed using the traditional models, which are based on a knowledge of the radial dimension(s) of the cells. Because of these and other features, we have initiated a study of the dielectric behaviour of animal cell cultures. The present article summarizes our studies of mouse L929-derived LS fibroblasts, a strain of importance in toxicological and other studies $[46,47]$.

\section{EXPERIMENTAL}

\section{Biological material}

Mouse L929-derived LS fibroblasts were maintained and grown as suspension cultures as previously described [47]. Volumes of $200-400 \mathrm{ml}$ were taken when the cells were in early stationary phase, harvested and washed twice by centrifugation at $700 \mathrm{~g}$ in a Beckman $\mathrm{J}-21$ centrifuge. The washing medium consisted of $0.3 \mathrm{M}$ sorbitol containing $1 \mathrm{~m} M \mathrm{KCl}, 1 \mathrm{~m} M \mathrm{NaCl}, 0.5 \mathrm{~m} M \mathrm{MgSO}_{4}$ and $5 \mathrm{~m} M$ 
Na-HEPES ( $\mathrm{pH} 7.0$ ), and the cells were finally resuspended in a small volume $(2-2.5 \mathrm{ml})$ of the same medium. Centrifugations were carried out at room temperature $\left(20-22^{\circ} \mathrm{C}\right)$ and all other operations at $37^{\circ} \mathrm{C}$. The cells were held at $37^{\circ} \mathrm{C}$ for up to $3 \mathrm{~h}$ before use. Under these conditions, they were able to manufacture significant quantities of (presumably lactic) acid from endogenous reserves, a process which ceased as judged by $\mathrm{pH}$ changes within a quarter of an hour. However, no noticeable effect of this on their dielectric behaviour could be discerned. Acid production could be inhibited by adding $0.5 \mathrm{~m} M$ iodoacetate, but this caused significant changes in the dielectric behaviour of the cells, so that this practice was not adopted. Viability, as assessed using trypan blue $[48,49]$, declined to some $80 \%$ during the first $90 \mathrm{~min}$ following resuspension, and remained in excess of $55 \%$ even after $4 \mathrm{~h}$ in the resuspension medium.

\section{Dielectric measurements}

These were made using a two-terminal Hewlett-Packard Model 4192A Impedance Analyser controlled by an HP85 microcomputer, described fully elsewhere [23,50,51]. Pt pin-type electrodes led directly to the measuring terminals of the impedance bridge. The dielectric cell was thermostatted at $37^{\circ} \mathrm{C}$.

\section{RESULTS}

Figure 1 shows a typical dielectric spectrum of LS cells between $0.1 \mathrm{kHz}$ and 13 $\mathrm{MHz}$ when suspended in the standard medium. As we have previously observed, using the same apparatus with suspensions of Saccharomyces cerevisiae [50] and a number of prokaryotic micro-organisms [23], a pronounced $\beta$-dispersion is apparent. The apparent dispersion below $10 \mathrm{kHz}$ and the decrease in conductivity above approximately $5 \mathrm{MHz}$ are instrumental artefacts caused respectively by electrode polarization and the inductances of the leads to the measuring cell, as may be discerned by comparing the data observed with an isoconductive ionic solution (Fig. 1A). As previously [23,50,51], we have found it worthwhile to display the data in complex plane plots of both permittivity and conductivity, the relevant values of the low-frequency conductivity $\sigma_{\mathrm{L}}^{\prime}$ and the high-frequency permittivity $\epsilon_{\infty}^{\prime}$ to be used in each case being obtained from such diagrams. It may be observed that whilst the complex permittivity (Cole/Cole [52]) plot (Fig. 1B) is well (though not perfectly) fitted by a single semi-circular locus, with a value for the Cole/Cole $\alpha$ in this experiment of some 0.17 , the complex admittance plot (Fig. 1C) shows evidence of a secondary dispersion centred at frequencies greater than those accessible using the present apparatus. To illustrate the problems of fitting the data exactly to a single dispersion, Fig. 1B displays the effects of the choice of "low-frequency" conductivity on the complex permittivity diagram. The semi-circular arc also plotted shows the means by which the dielectric increment was obtained. The value of the "high-frequency" permittivity obtained with this arc was used to construct the complex admittance diagram shown in Fig. 1C. The characteristic frequency, as derived from the complex permittivity plot, was approximately $100 \mathrm{kHz}$ in this 

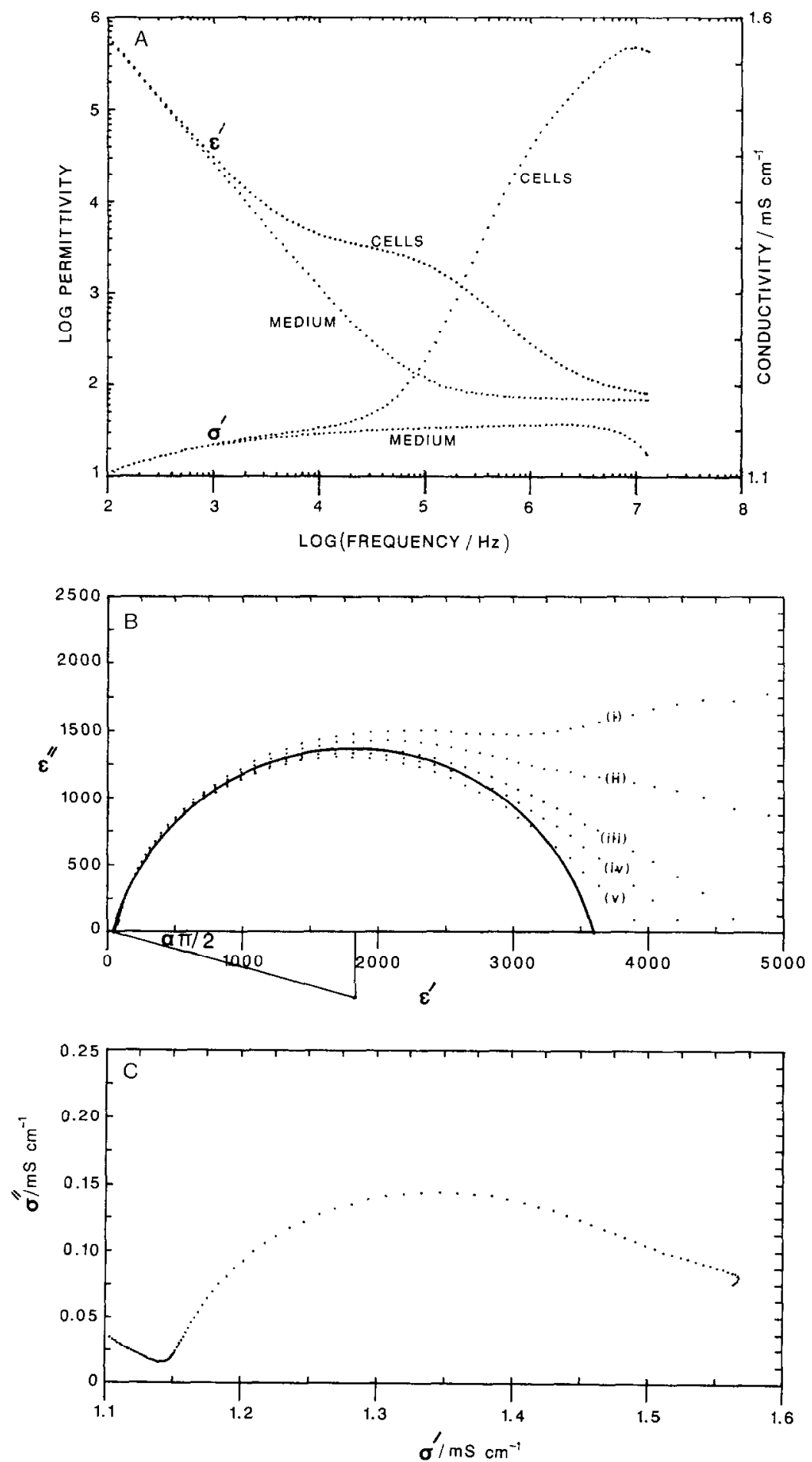
medium, and no significant $\alpha$-dispersion could be discerned. Similar observations have recently been made using rat basophil leukaemia cells [35,36].

To ensure that the dielectric behaviour being studied was fully ascribable to the cells alone, and that the electrode polarization phenomena inevitably associated with two-terminal measurements $[2,4,17]$ were accurately discounted, we performed experiments similar to those of Fig. 1 using suspensions in which the volume fraction of the suspended phase was varied systematically. Using the same type of data analysis as in that figure, we plotted the dielectric increment $\Delta \epsilon^{\prime}$ obtained from the complex permittivity diagrams as a function of the cellular biomass present, in two separate ways (Fig. 2). Figure $2 \mathrm{~A}$ shows a plot $\Delta \epsilon^{\prime}$ vs. the cell number as obtained from haemocytometer counts. Figure $2 \mathrm{~B}$ shows a similar plot of $\Delta \epsilon^{\prime}$ vs. the volume fraction of the suspended phase as calculated from the cell numbers and radii. Figure 2B also shows the data to be expected on the bases that (i) the cells were perfect spheres of their observable radius $(r=6.4 \pm 0.1 \mu \mathrm{m})$, (ii) they had a plasma membrane capacitance $C_{\mathrm{m}}$ of $1 \mu \mathrm{F} / \mathrm{cm}^{2}$, (iii) their volume fraction $P$ could be calculated from the observable radii and cell numbers, and (iv) that the dielectric increment $\Delta \epsilon^{\prime}$ of the $\beta$-dispersion was given [1] by

$\Delta \epsilon^{\prime}=9 \operatorname{Pr} C_{\mathrm{m}} / 4 \epsilon_{0}$

where $\epsilon_{0}=8.854 \times 10^{-12} \mathrm{~F} / \mathrm{m}$. We also sought to estimate $P$ using the conductimetric method described [54,55]; however, the cell radii were observed to change significantly in the highly-conducting media necessary for this estimation. In all cases, strict linearity of $\Delta \epsilon$ ' with "biomass" was observed over the range of cell numbers (volume fractions) studied, which serves to indicate both that the dielectric behaviour assessed was purely due to the presence of the cells and that the dielcctric method of biomass estimation would be suitable for use with the animal cells. In the example shown in Fig. 2A, the specific dielectric increment observed was some 34 permittivity units per $10^{6} \mathrm{cells} / \mathrm{ml}$. In a series of experiments carried out over a period of 6 months, however, long-term variations in this parameter in the range $30-70$ permittivity units per $10^{6}$ cells $/ \mathrm{ml}$ were noted for cells harvested from different batch cultures.

Fig. 1. Dielectric behaviour of anchorage-independent mouse L929-derived LS fibroblasts, in the frequency range $100 \mathrm{~Hz}-13 \mathrm{MHz}$. Measurements were carried out on a suspension containing $1.28 \times 10^{8}$ cells $/ \mathrm{ml}$ in the medium ( $0.3 M$ sorbitol, $0.5 \mathrm{~m} \mathrm{M} \mathrm{MgSO}_{4}, 1 \mathrm{~m} \mathrm{M} \mathrm{NaCl}, 1 \mathrm{~m} M \mathrm{KCl}, 5 \mathrm{~m} M$ Na-HEPES, starting $\mathrm{pH}$ 7.0) described in the Experimental section. (A) Permittivity and conductivity vs. the logarithm of the measuring frequency. A spectrum of the suspension medium, whose conductivity was adjusted to the same "low-frequency" value as that of the suspension, using small aliquots of $\mathbf{K C l}$, is shown for comparative purposes. (B) Complex permittivity ("Cole/Cole") diagram of the data for the cell suspension in (A). The values of the "low-frequency" conductivity (in $\mathrm{mS} \mathrm{cm}^{-1}$ ) to be subtracted for obtaining the parameters of the $\beta$-dispersion were: (i) 1.143 , (ii) 1.147 , (iii) 1.151 , (iv) 1.153 and (v) 1.155 . The "best fit" to a semi-circular locus (plot (iii)) was made by eye and is also illustrated together with the (usual) means by which the Cole $\alpha$ was obtained. (C) Complex admittance diagram of the data in (A). The value of the "high-frequency" permittivity used was 71 , and was obtained from the "best fit" shown in $(\mathrm{B})$. 


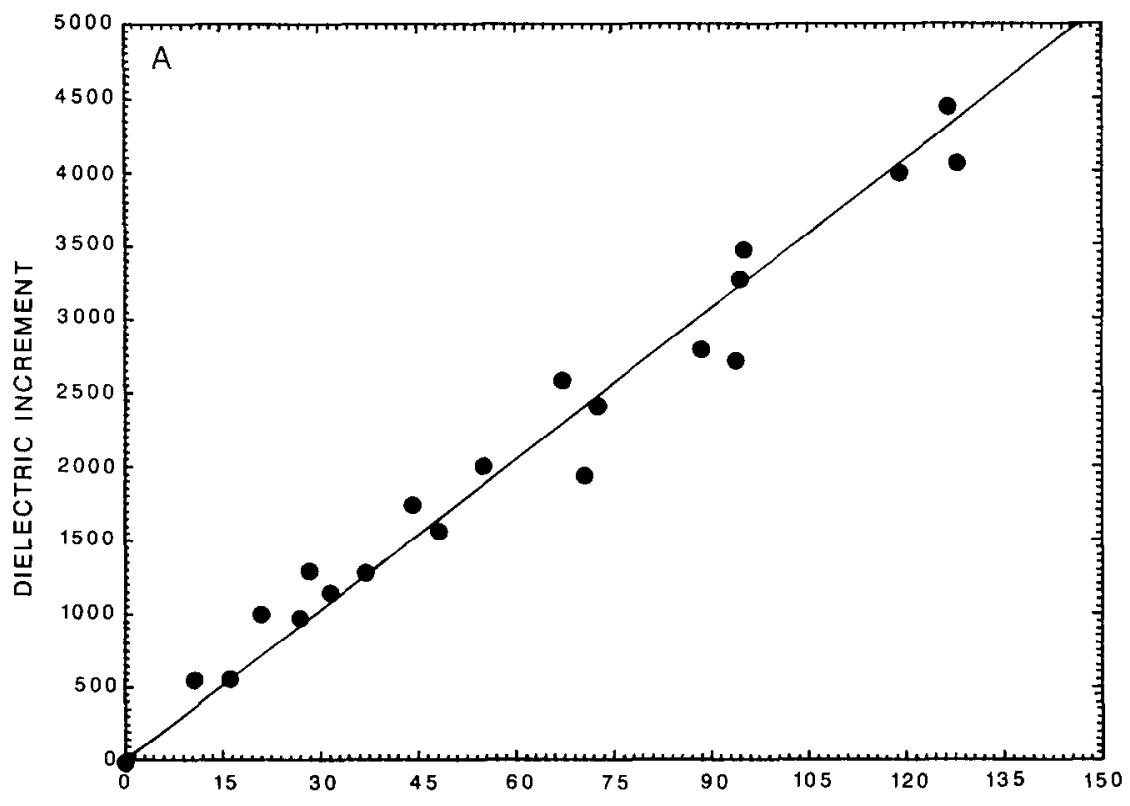

10E-6 X CELL NUMBER/m!

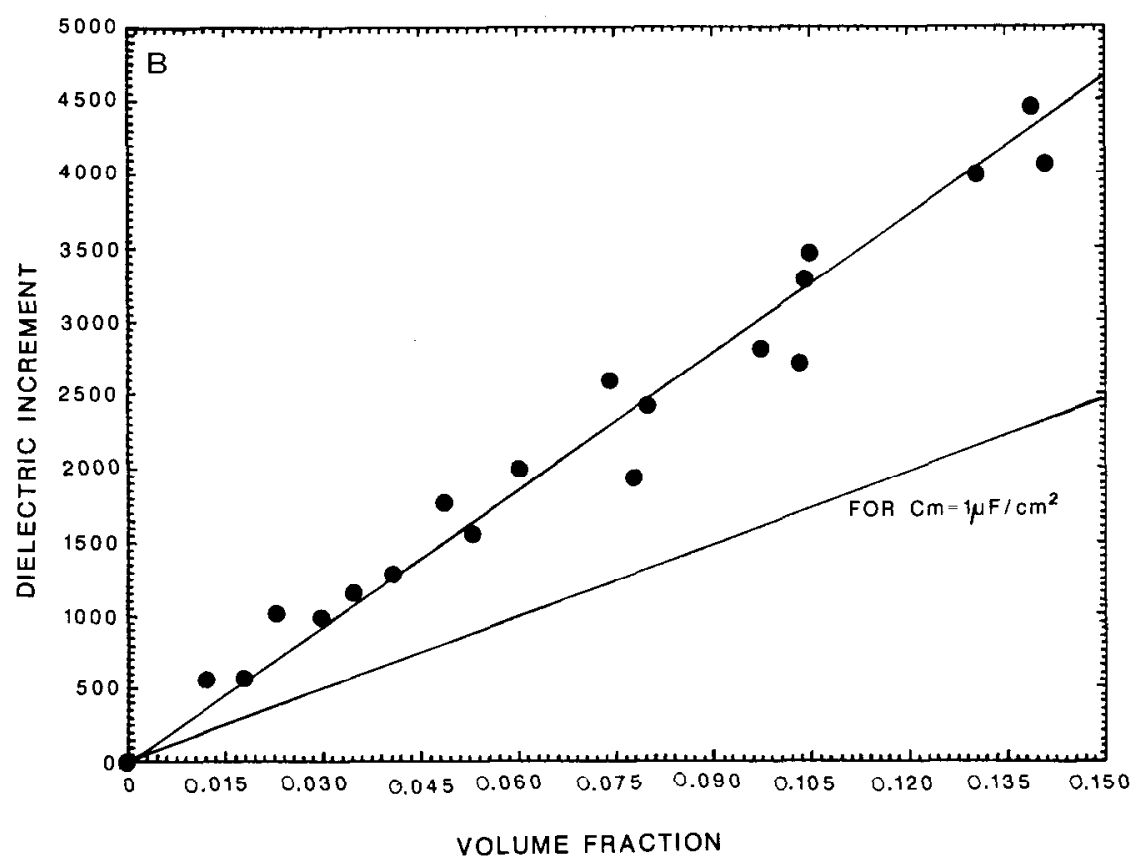

Fig. 2. Effect of the cell concentration on the dielectric increment of the $\beta$-dispersion of mouse LS cells. Measurements were made exactly as described in the legend to Fig. 1, except that the cell numbers were varied as shown. (A) Dielectric increment vs. cell number per $\mathrm{ml}$. The line is fitted by eye. (B) Dielectric increment vs. volume fraction as calculated from the cell numbers and radii on the assumption that the cells are spheres of their observable diameter. The line is fitted by eye. The diagram also shows the data to be expected if the $\beta$-dispersion is simply due to the charging of spherical cell membrane capacitance of $1 \mu \mathrm{F} / \mathrm{cmi}^{2}$. Over a range of such diagrams, the Cole $/$ Cole $\alpha$ was $0.13 \pm 0.03 \mathrm{SD}$. 


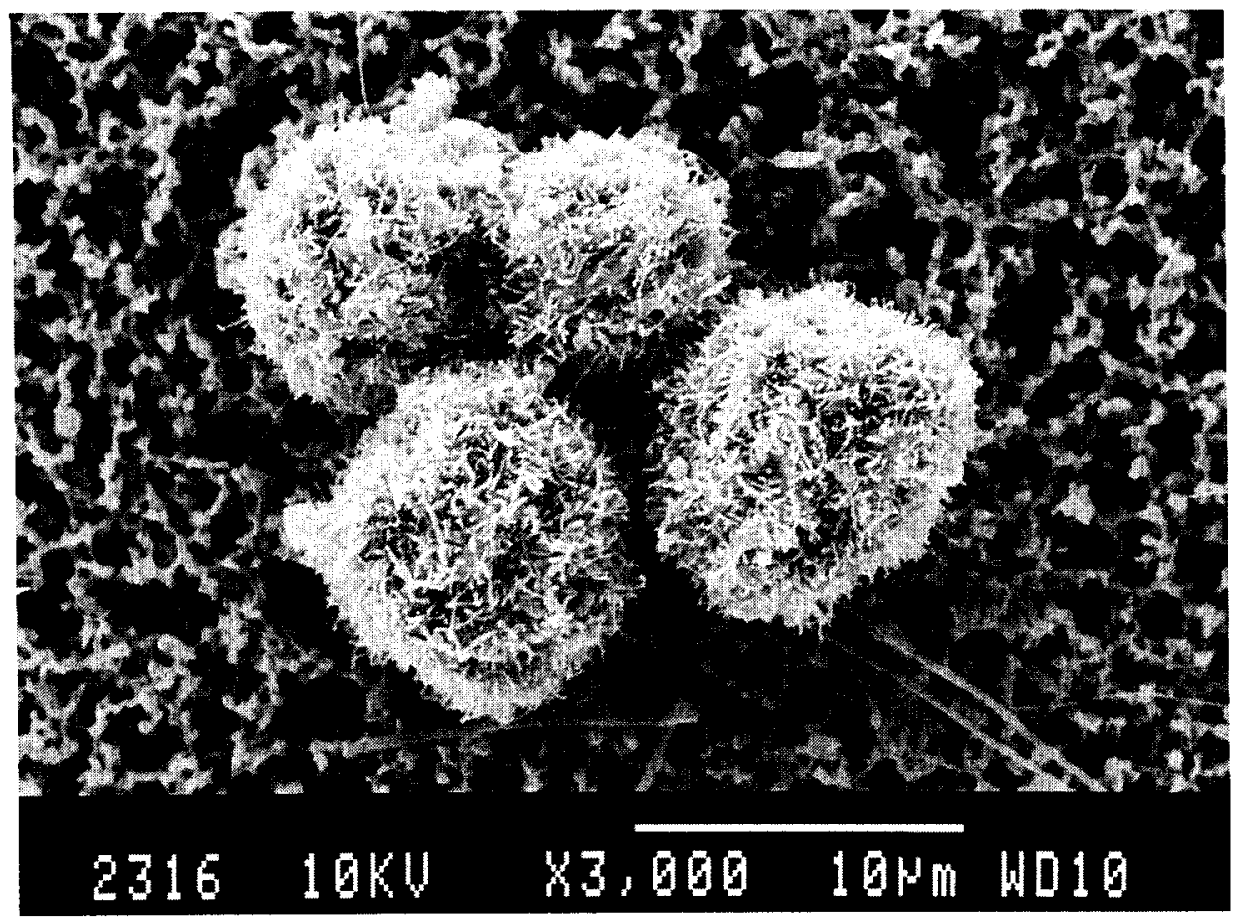

Fig. 3. Scanning electron micrograph of the LS cells used in the present work. Owing to cell shrinkage during the electron microscopic preparation, the observable diameter is smaller, and the villosity greater, than that existing in culture. The purpose is merely to illustrate that the cells cannot be deemed to be perfectly spherical. The cells were resuspended in $10 \mathrm{ml}$ of fixative (1\% formaldehyde, $1 \%$ glutaraldehyde, 1 drop of $2 \%$ osmium tetroxide and buffered to $\mathrm{pH} 7.2$ with sodium cacodylate) before being gently syringed onto a millipore filter. The filter was then soaked in the fixative for $1 \mathrm{~h}$, rinsed, post-fixed in $1 \%$ osmium tetroxide, dehydrated in an ethanol series, transferred to fluorisol and then critical point dried in $\mathrm{CO}_{2}$.

Given the accuracy of the radius measurements and, in principle, of the haemocytometer counts, the slope of such a plot may be used to obtain the value of the specific membrane capacitance from eqn. (1). Even for the relatively low specific dielectric increment possessed by the cells used in the experiment of Fig. 2 , the value so obtained is some $1.90 \mu \mathrm{F} / \mathrm{cm}^{2}$, which is significantly greater then the widely accepted value $[3,14,16]$ of $1 \mu \mathrm{F} / \mathrm{cm}^{2}$. The most plausible reasons for this are that (a) factors other than a simple Maxwell-Wagner effect of charging a "static" membrane capacitance contribute to the $\beta$-dispersion $[14,16]$ and/or (b) the theory is based on the assumption that the cells are perfectly spherical objects. However, animal cells in general, and LS cells in particular, exhibit numerous membrane protrusions (Fig. 3); the presence of such protrusions will tend significantly to increase the actual membrane area and hence the apparent specific membrane capacitance estimated on the basis that the cells are spherical shells, a point also stressed in this context by the Kochi group $[35,36]$. 
To see if this type of mechanism was indeed the dominant reason for the large apparent capacitance of the plasma membrane of LS cells, we decided to attempt to "sphericalize" them by destroying elements of the cytoskeleton which are thought [53,55-58] to maintain the cells' very convoluted morphology. However, neither treatment of the cells at $0^{\circ} \mathrm{C}$ for up to $2 \mathrm{~h}$ nor the addition of appropriate concentrations of cytochalsin $\mathrm{B}$ nor colchicine served to achieve the desired effect. Therefore we adopted the approach exploited by Irimajiri et al. [36], who studied the
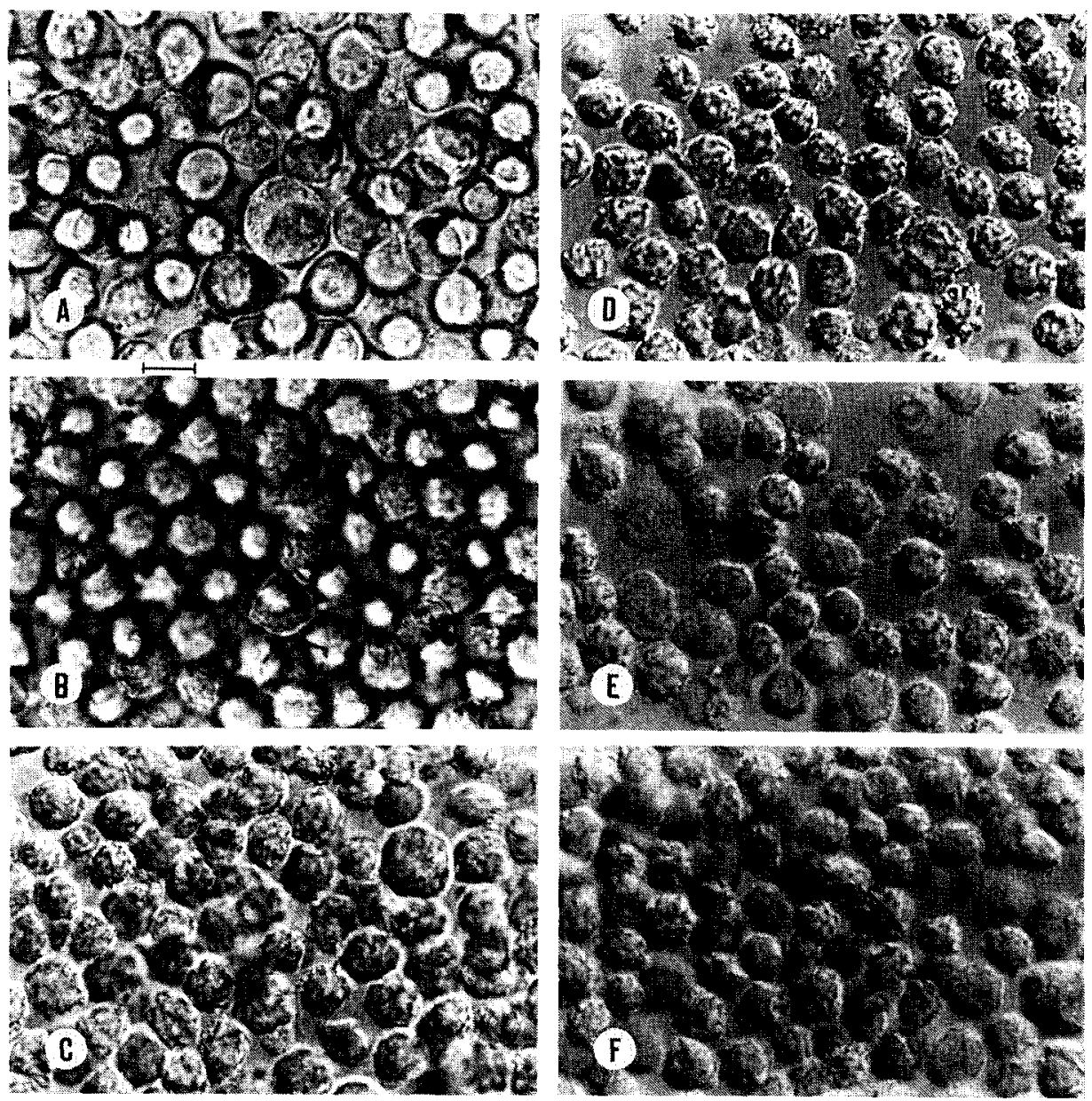

Fig. 4. Effect of the medium osmolarity on the morphology of mouse LS cells, observed using Nomarski optics. Cells were resuspended in the medium described in the legend to Fig. 1, except that the osmolarity was varied with the additional concentrations of sorbitol indicated. It may be observed that the surface roughness or villosity was greatly increased in the hyperosmotic media. The bar equals $12 \mu \mathrm{m}(1 \mathrm{~mm}=2$ $\mu \mathrm{m}$ ). Additional osmolarities of sorbitol were: (A) 0 (control); (B) 0.1 ; (C) $0.2 ;$ (D) 0.4 ; (E) 0.6 ; and (F) 1.0 . 


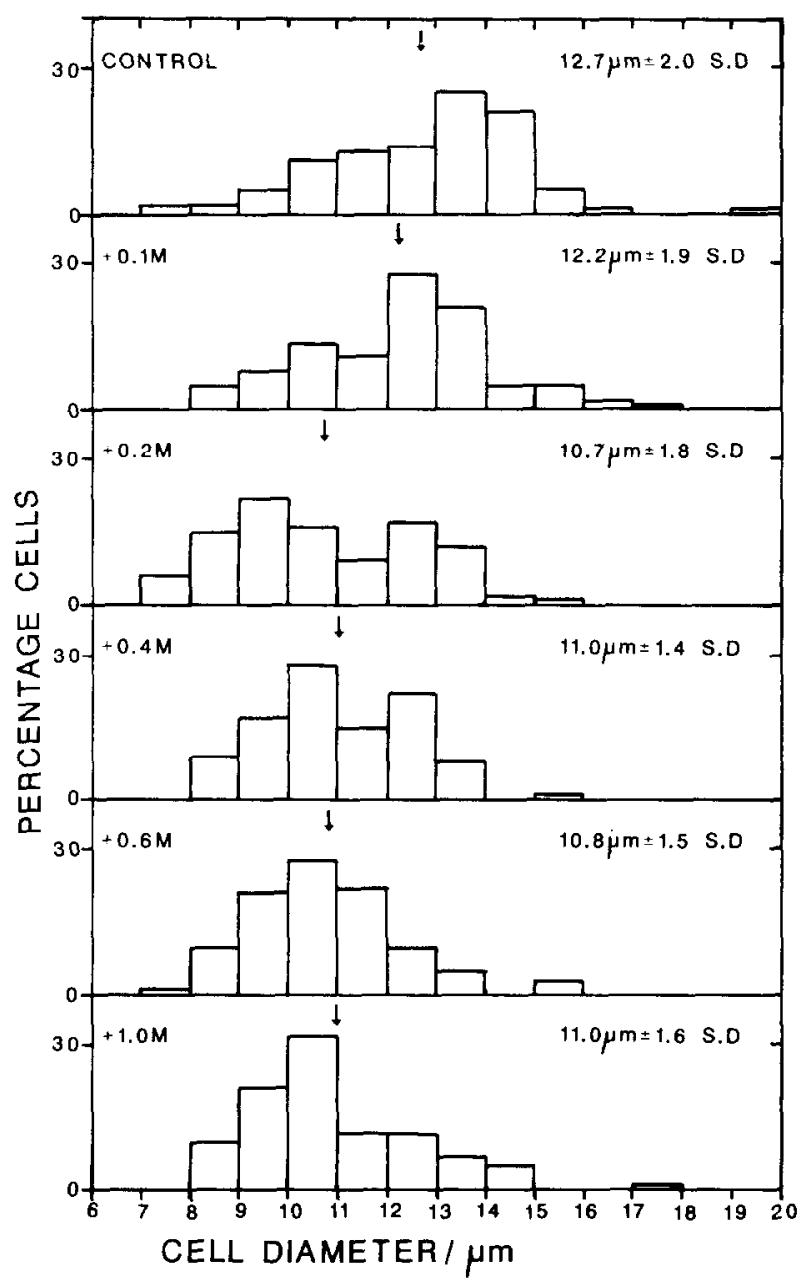

Fig. 5. Histograms of the cell diameters observed in the suspensions shown in Fig. 4. Means are given by the arrows whilst the standard deviations are as indicated.

effect of the osmolarity of the external medium on the dielectric behaviour of rat basophil leukaemia cells.

Sorbitol is known to be a suitable osmoticum for animal cells, including L-929 cells $[48,49,59]$, since it is essentially membrane-impermeable on a time-scalc greatly in excess of that of relevance to the present experiments. The effect of additions of varying concentrations of sorbitol to the standard medium on the gross appearance and the cell size distribution is indicated in Figs. 4 and 5, respectively. It may be observed, as expected, both that the cell radii are decreased and that the villosity of the cellular surface is greatly increased by suspension of the cells in increasingly hypertonic media. 


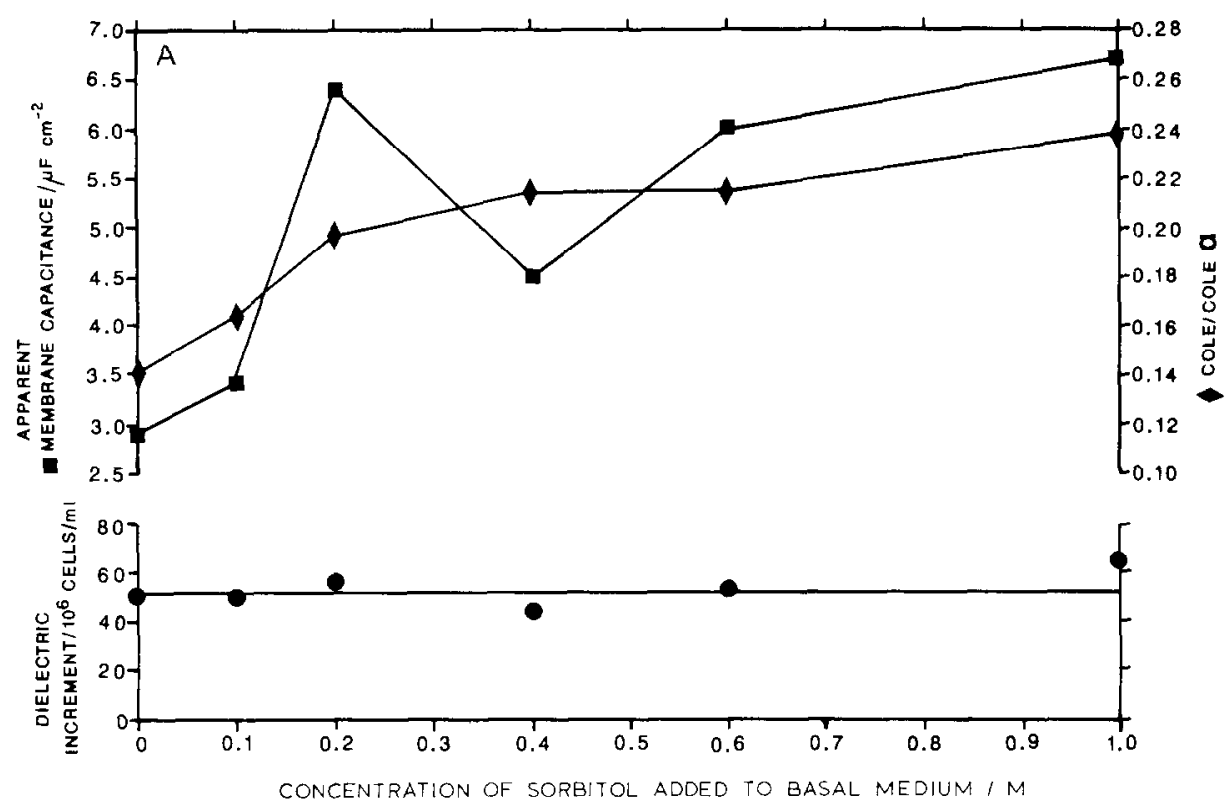

Fig. 6. Effect of medium osmolarity on the dielectric behaviour of mouse LS cells. Measurements were made on the cell suspensions shown in Figs. 4 and 5 exactly as described in the legend to Figs. 1 and 2 , except that the osmolarity of the medium was varied as indicated.

When dielectric measurements were performed on such suspensions, the following features, summarized in Fig. 6, became apparent: as the osmolarity was increased, (1) the dielectric increment per $10^{6} \mathrm{cells} / \mathrm{ml}$ was virtually unchanged (at, in this case, a value of $54 \pm 3$, mean \pm SEM), (2) the Cole/Cole $\alpha$ value increased substantially, and (3) the apparent, membrane capacitance increased. These findings are collectively very similar to those observed by the Japanese group [36]. However, the secondary dispersion, which was just noticeable at high frequencies in the complex admittance plot when cells were suspended in the standard medium (Fig. 1 ), was very greatly and monotonically increased in media of high osmolarity, and Fig. 7 shows data to illustrate this. While the fact that our present equipment is limited to frequencies below $13 \mathrm{MHz}$ means that it was not possible to measure the entire secondary dispersion, it is quite evident, as may also be clearly seen in the study of Irimajiri et al. [36], that the data may still be reasonably well fitted to a

Fig. 7. Dielectric behaviour of mouse LS cells in a hyperosmotic medium. Measurements were made exactly as described in the legend to Fig. 1, except that the final sorbitol concentration was $0.7 M$ (i.e. an additional $0.4 \mathrm{M}$ sorbitol was present) and the cell concentration was $5.5 \times 10^{7} \mathrm{ml}^{-1}$. (A) Permittivity and conductivity vs. the logarithm of the frequency. (B) Complex permittivity diagram(s) using values for the "low-frequency" conductivity (in $\mathrm{mS} \mathrm{cm}^{-1}$ ) of the $\beta$-dispersion of (i) 0.7950 , (ii) 0.7960 , (iii) 0.7970 , (iv) 0.7980 . (v) 0.7985 and (vi) 0.8000 . The locus chosen was (iv). (C) Complex admittance diagram using the value of the "high-frequency" permittivity (70) obtained in (B). 

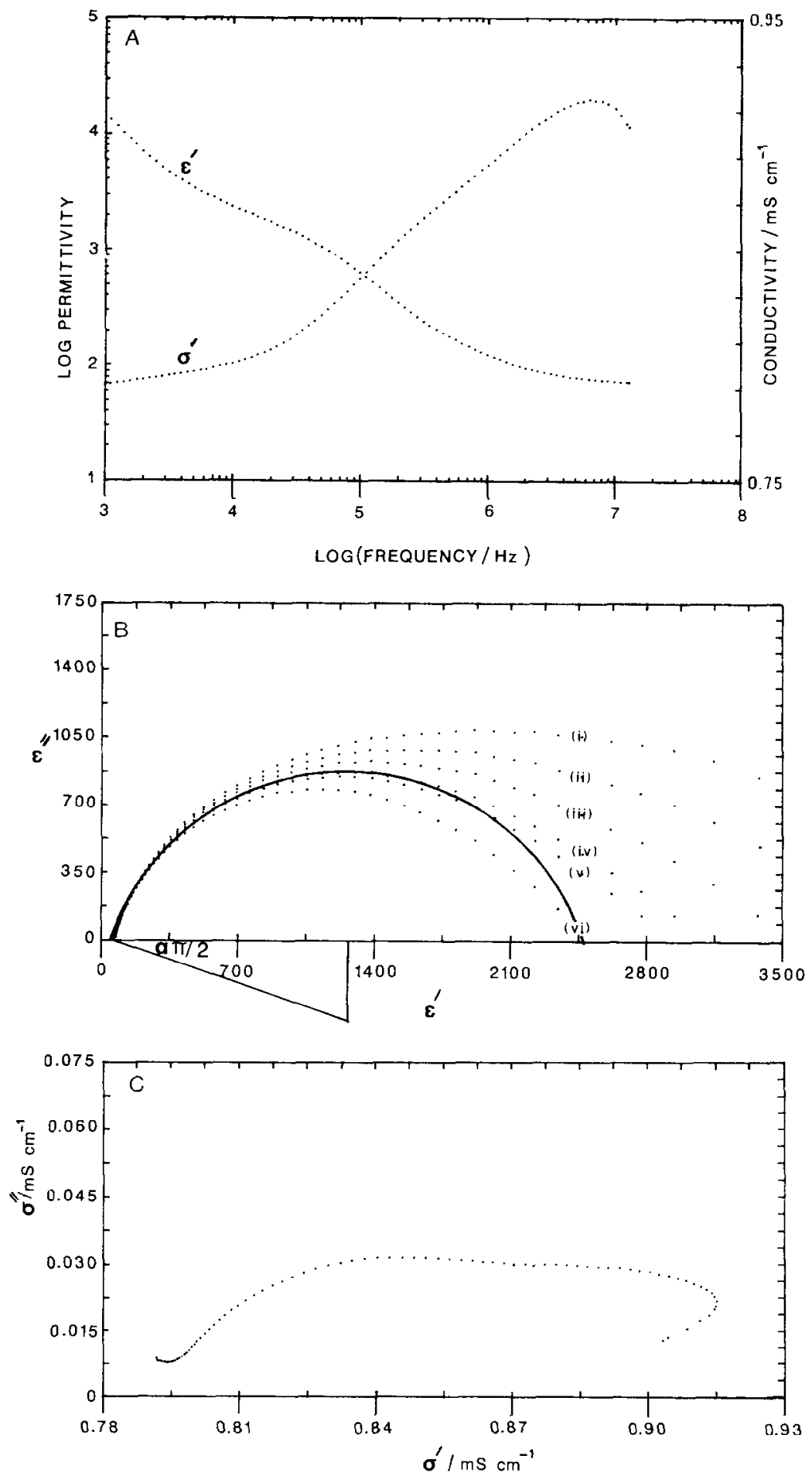
single Cole/Cole locus, on the one hand, but indicate two quite separate dispersions when observed in the complex admittance plane, on the other hand. This general type of finding, which is becoming increasingly widespread as studies of the dielectric behaviour of biological $[4,5,15,60,61]$ and other $[17,62,63]$ system become more sophisticated, illustrates the point that most real systems are not Kronig-Kramers transformable and thus $[15,61]$ that one or more of the assumptions underlying classical linear dielectric theory, particularly that of local equilibrium, are inapplicable.

As regards the exploitation of the dielectric method in the estimation of the biomass of growing animal cell cultures, where one would preferably make measurements at frequencies towards the lower end of the $\beta$-dispersion [21], we had hoped to obtain a value for the internal conductivity $\left(\sigma_{\mathrm{i}}{ }^{\prime}\right)$ of these cells using the equations derived by Schwan $[1,7,14,16,21,37]$. This would permit us to obtain the value of the characteristic frequency to be expected in growth media [64] which have a conductivity some ten-fold greater than that used (for reasons of minimizing the contribution of electrode polarization to the dielectric data) in the present work, and thus a value for the appropriate measuring frequency to use. However, three major problems beset this endeavour. Firstly, it is now understood that the aqueous cytoplasm possesses a significant organizational structure such that the "conductivity" measured will itself depend on the frequency of measurement, and does not therefore exhibit a sharp value $[16,59,65]$ even when the frequency of measurement is great enough to reflect what is usually referred to as the "high-frequency" conductivity $\sigma_{\infty}^{\prime}[16]$. Secondly, the model is less than adequate for cells exhibiting a significant degree of microvillosity [35]; and thirdly, we found (data not shown) that the value of $\sigma_{\mathrm{i}}^{\prime}$ estimated is so sensitive to the data obtained as to make the attempt rather worthless.

\section{DISCUSSION}

The present work has shown that, in common with all other biological cells, mouse LS cells exhibit a pronounced dielectric dispersion in the frequency range 10 $\mathrm{kHz}-10 \mathrm{MHz}$, which is usually referred to as the $\beta$-dispersion. The classical explanation of this behaviour, dating from Fricke's work [66], ascribes this dispersion to the charging of a "static" membrane capacitance represented by the plasma membrane of the cells which, due to its molecular thickness, possesses an electrical capacitance of some $1 \mu \mathrm{F} / \mathrm{cm}^{2}$. This view is well summarized in Cole's monograph [3]. However, deviations from this "textbook" value of $1 \mu \mathrm{F} / \mathrm{cm}^{2}$ are far from uncommon, and indeed a consideration of the permittivity and thickness of biological and black lipid membranes indicates clearly that even $1 \mu \mathrm{F} / \mathrm{cm}^{2}$ is roughly double the value that should be expected for the described mechanism $[14,16]$. A variety of membrane-associated properties, such as more-or-less restricted lateral lipid, protein and double-layer ion mobility, and field-induced conformational transitions of membrane proteins, may serve to account for this discrepancy. 
Notwithstanding, a number of studies have pointed out the importance of considering the true geometric area of a membrane when assessing its capacitance from ac electrical methods. Thus, early work by Cole [42] and by Iida [43] showed a significant increase in $C_{\mathrm{m}}$ upon fertilization, and it was Rothschild [44] who determined that this was caused by, or at least correlated with, a significant increase in the area of the cytoplasmic membrane of the cells. Similarly, Fernandez et al. [67], using whole-cell clamp measurements, were able to observe such increases in $C_{\mathrm{m}}$ in single degranulating mast cells directly. In this context, one must of course mention the discovery of the T-system of skeletal muscle by Fatt [68], who had used dielectric methods to obtain an apparent value of $C_{\mathrm{m}}$ of more than $50 \mu \mathrm{F} / \mathrm{cm}^{2}$. Finally, a recent study by Irimajiri et al. obtained unrealistically large values for $C_{\mathrm{m}}$ which correlated accurately with the microvillosity of the plasma membrane of rat basophil leukaemia cells, and which they ascribed to this type of effect. It is noteworthy that both Cole [3] and Irimajiri et al. [35,36], as did we ourselves, nevertheless obtained rather small values of the Cole/Cole $\alpha$ (in isosmotic media) when fitting their data to the Cole/Cole equation, indicating that this property of evaginated membranes did not cause a gross distribution in the relaxation time(s) of the $\beta$-dispersion observed in the complex permittivity domain.

In the present work, we determined a value for the apparent membrane capacitance of mouse LS cells of some 1.7 to $4.0 \mu \mathrm{F} / \mathrm{cm}^{2}$ (depending on the batch of cells, although the week-to-week variation was much less than this), consistent with the above type of interpretation. Further, as with the related studies of the Japanese group [35,36], a secondary dispersion at higher frequencies, which was much enhanced by increasing the extracellular osmolality, could be discerned in the complex admittance, but not the complex permittivity, diagrams of the (same) data. Although it is probable that a Maxwell-Wagner type of dispersion caused by intracellular organelles might contribute to the "secondary" or $\beta_{2}$-dispersion $[7,15,35,36]$, it is not clear how this contribution might be expected to have an osmolality-dependent increase in dielectric increment. (Additionally, the rather modest values of $\epsilon_{\infty}^{\prime}$ that we calculated from the complex permittivity diagrams make this interpretation alone somewhat implausible.) More likely, in our opinion, is the fact that any restriction on the motions of ions will give rise to a dielectric dispersion, so that a more-or-less separate dielectric dispersion should be caused, via a classical Maxwell-Wagner type of mechanism, simply by the existence of the membrane protrusions themselves (Fig. 8). This would be expected to have a higher characteristic frequency than that of the main dispersion, by an extent in approximate proportion to the relevant "radius" of the quasi-cylindrical protrusions, and to have a dielectric increment which was increased by the degree of microvillosity. Further, such a mechanism of dielectric relaxation, which is illustrated in Fig. 8, would be expected to overlap the classical $\beta$-dispersion with which it is mechanistically and physically contiguous, and, by manifesting predominantly in the complex admittance domain (due to its higher characteristic frequency), to cause an apparent increase in the Cole/Cole $\alpha$ when data are fitted to the Cole/Cole equation. Interestingly enough, this is precisely the behaviour observed (Fig. 6). 


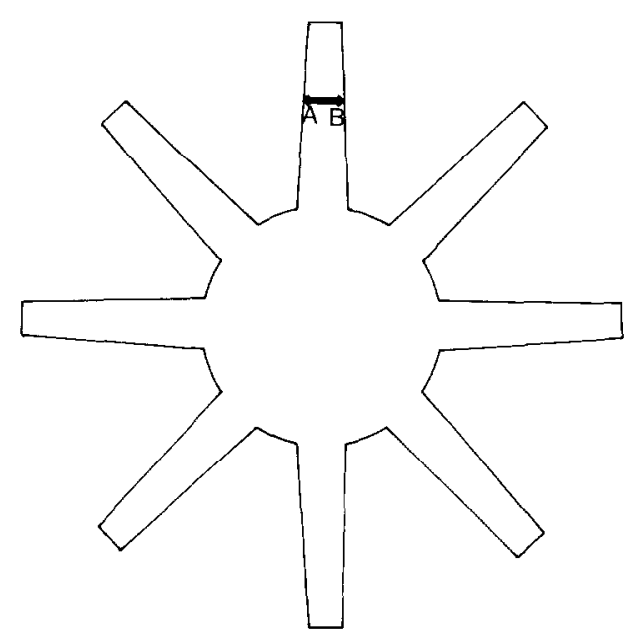

Fig. 8. Diagram to illustrate the effect of surface villosity in broadening the classical $\beta$-dispersion. It is assumed that the electrodes are on the left- and right-hand sides of the page. Because of the presence of membrane protrusions with a "radius" (between points such as A and B) and relaxation times smaller than that of the cell with which they are contiguous, the $\beta$-dispersion will tend to be broadened at higher frequencies, the effect being more apparent in the complex admittance domain (due to its relative "weighting" [17]), and will be increased as the amount of villosity is increased such that at very high extents of villosity it will manifest as a separate dispersion which may itself be expected to be contiguous with the "main" $\beta$-dispersion.

Although such complications rather bedevil a quantitative interpretation of the dielectric behaviour of these cells at high radio-frequencies, variations in the cells' morphology caused by their natural possession of membranous protrusions, which might themselves be a function of physiological status, have rather a modest effect on the specific dielectric increment of these suspensions, at least when the osmolarity of the external medium is changed. Happily, this strongly favours the utility of the dielectric method of biomass estimation $[20,21]$ in animal cells since, in addition, the permittivity of these cells at low radio-frequencies is strictly linear with the volume fraction of the suspended phase.

\section{ACKNOWLEDGEMENTS}

We thank the Biotechnology Directorate of the Science and Engineering Research Council, U.K. for financial assistance, Dr. Iolo ap Gwynn for useful discussions, and Anthony Pugh for photographic assistance.

\section{REFERENCES}

1 H.P. Schwan, Adv. Biol. Med. Phys., 5 (1957) 147.

2 H.P. Schwan in W.L. Nastuk (Ed.), Physical Techniques in Biological Research, Vol. 6B, Academic Press., New York, 1963, p. 323. 
3 K.S. Cole, Membranes, Ions and Impulses, University of California Press, Berkeley, 1963.

4 E.H. Grant, R.J. Sheppard and G.P. South, Dielectric Behaviour of Biological Molecules in Solution, Oxford University Press, Oxford, 1978.

5 R. Pethig, Dielectric and Electronic Properties of Biological Materials, Wiley, Chichester, 1979.

6 R. Pethig, IEEE Trans. Electr. Insul., 19 (1984) 453.

7 H.P. Schwan and K.P. Foster, Proc. IEEE, 68 (1980) 104.

8 W.R. Adey, Physiol. Rev., 61 (1981) 435.

9 R.O. Becker and A.A. Marino, Electromagnetism and Life, Suny Press, Albany, NY, 1982.

10 A. Kraszewski, M.A. Stuchly, S.S. Stuchly and A.M. Smith, Bioelectromagnetics, 3 (1982) 421.

11 R.L. Magin and E.C. Burdette in P. Rolfe (Ed.), Non-Invasive Physiological Measurements, Vol. 2, Academic Press., New York, 1983.

$12 \mathrm{H}$. Berg in R. Kalvoda and R. Parsons (Eds.), Electrochemistry in Research and Development, Plenum Press, New York, 1985, p. 227.

13 R.O. Becker and G. Selden, The Body Electric: Electromagnetism and the Foundation of Life, William Morrow, New York, 1985.

14 D.B. Kell and C.M. Harris, J. Bioelectr., 4 (1985) 317.

15 K.R. Foster and H.P. Schwan in C. Polk and E. Postow (Eds), CRC Handbook of Biological Effects of Electromagnetic Fields, CRC Press, Boca Raton, FL, 1986, p. 27.

16 R. Pethig and D.B. Kell, Phys. Med. Biol., 32 (1987) 933.

17 D.B. Kell in A.P.F. Turner, I. Karube and G.S. Wilson (Ed.), Biosensors: Fundamentals and Applications, Oxford University Press, Oxford, 1987, p. 427.

18 D.B. Kell, Univ. Wales Rev. Sci. Technol., 1 (1987) 64.

19 D.B. Kell, J. Gen Microbiol., 133 (1987) 1651.

20 D.B. Kell, C.M. Samworth, R.W. Todd, S.J. Bungard and J.G. Morris, Stud. Biophys., 119 (1987) 153.

21 C.M. Harris, R.W. Todd, S.J. Bungard, R.W. Lovitt, J.G. Morris and D.B. Kell, Enzyme Microbial Technol., 9 (1987) 181.

22 D.R. Kell and C.M. Harris, Fur. Biophys. J., 12 (1985) 181.

23 C.M. Harris and D.B. Kell, Eur. Biophys. J., 13 (1985) 11.

24 M. Symons, R. Korenstein, C.M. Harris and D.B. Kell, Bioelectrochem. Bioenerg., 16 (1986) 45.

25 J.R. Birch, R. Boraston and L. Wood, Trends Biotechnol., 3 (1985) 162.

26 A. Fiechter (Ed.), Vertebrate Cell Culture I, Springer, Heidelberg, 1987.

27 T. Cartwright, Trends Biotechnol., 5 (1987) 25.

28 G. Martinez-Lopez and L.M. Black, Methods Cell Biol., 15 (1977) 407.

29 C.M. Harris and D.B. Kell, Biosensors, 1 (1985) 17.

30 O. Merten and G.E. Palfi, Dev. Biol. Standard., in press.

31 O. Merten, G.E. Palfi and J. Steiner, Adv. Biotechnol. Proc., in press.

32 A. Irimajiri, T. Hanai and A. Inouye, Biophys. Str. Mech., 1 (1975) 273.

33 A. Irimajiri, Y. Doida, T. Hanai and A. Inouye, J. Membr. Biol., 38 (1978) 209.

34 W. Jaroszynski, J. Terlecki, A. Myśliswki, J. Myśliswka and J. Witkowski, Folia Histochem. Cytochem., 21 (1983) 161.

35 A. Irimajiri, K. Asami, T. Ichinowatari and Y. Kinoshita, Biochim. Biophys. Acta, 896 (1987) 203.

36 A. Irimajiri, K. Asami, T. Ichinowatari and Y. Kinoshita, Biochim. Biophys. Acta, 896 (1987) 214.

37 H. Pauly and H.P. Schwan, Z. Naturforsch. Teil B, 14 (1959) 125.

38 T. Hanai, N. Koizumi and A. Irimajir, Biophys. Struct. Mech., 1 (1975) 285.

39 T. Hanai, A. Ishikawa and N. Koizumi, Bull. Inst. Chem. Res. Kyoto Univ., 55 (1977) 376.

40 A. Irimajiri, T. Hanai and A. Inouye, J. Theor. Biol., 78 (1979) 251.

41 K. Asami, T. Hanai and N. Koizumi, Jpn. J. Appl. Phys., 19 (1980) 359.

42 K.S. Cole, J. Gen. Physiol., 18 (1935) 877.

43 T.T. Iida, J. Fac. Sci. Imp. Univ. Tokyo, Sect. 4, 6 (1943) 165.

44 Rothschild, J. Biophys. Biochem. Cytol., 3 (1957) 103.

45 B.B. Mandelbrot, The Fractal Geometry of Nature, Freeman, San Francisco, 1982.

46 M. Balls, R.J. Riddell and A. Worden (Eds), Animals and Alternatives in Toxicity Testing, Academic Press, New York, 1983. 
47 R.B. Kemp, R.W.J. Meredith and S.H. Gamble, Food Chem. Toxicol., 23 (1985) 267.

48 J.S. Clegg, J. Cell. Physiol., 129 (1986) 367.

49 J.S. Clegg, J. Gallo and E. Gordon, Exp. Cell Res., 163 (1986) 35.

50 C.M. Harris and D.B. Kell, Bioelectrochem. Bioenerg., 11 (1983) 15.

51 D.B. Kell, Bioelectrochem. Bioenerg., 11 (1983) 405.

52 K.S. Cole and R.H. Cole, J. Chem. Phys., 9 (1941) 341.

53 A. Irimajiri, T. Hanai and A. Inouye, Experientia, 31 (1975) 1373.

54 R.W. Lovitt, R.P. Walter, J.G. Morris and D.B. Kell, Appl. Microbiol. Biotechnol., 23 (1986) 168.

55 N. Hirokawa and J.E. Heuser, J. Cell Biol., 91 (1981) 399.

56 B. Alberts, D. Bray, J. Lewis, M. Raff, K. Roberts and J.D. Watson, Molecular Biology of the Cell, Garland, New York, 1983, p. 550.

57 M. Schliwa, The Cytoskeleton, Springer, Heidelberg, 1986.

58 D. Solfer (Ed.), Dynamic Aspects of Microtubule Biology, New York Academy of Sciences, New York, 1986.

59 J.S. Clegg, Am. J. Physiol., 234 (1984) R133.

60 O.F. Schanne and E.R.P. Ceretti, Impedance Measurements in Biological Cells, Wiley, Chichester, 1978.

61 D.B. Kell, R.D. Astumian and H.V. Westerhoff, Ferroelectrics, in press.

62 J.R. MacDonald, IEEE Trans Electr. Insul., 15 (1980) 65.

63 A.K. Jonscher, Dielectric Relaxation in Solids, Chelsea Dielectrics Press, London, 1983.

64 D.B. Kell and A. Burns, J. Bioelectr., 5 (1986) 139.

65 A. M. Mastro and D.J. Wurley in G.R. Welch and J.S. Clegg (Eds.), The Organization of Cell Metabolism, Plenum Press, New York, 1987, p. 57.

66 H. Fricke, J. Gen. Physiol., 9 (1925) 137.

67 J.M. Fernández, E. Neher and B.D. Gomperts, Nature, 312 (1984) 453.

68 P. Fatt, Proc. R. Soc. London, Ser. B, 159 (1964) 606. 